\title{
How to build a cross-disciplinary institute: the curious case of the South American Institute for Resilience and Sustainability Studies
}

\author{
Marten Scheffer ${ }^{1,2}$ and Nestor Mazzeo ${ }^{2,3}$
}

\begin{abstract}
There is no recipe for setting up a new institute, especially if it is meant to be different from anything that currently exists. Here, we give a look behind the scenes at how we dreamt up the transdisciplinary South American Institute for Resilience and Sustainability Science (SARAS), located in Uruguay, and how, with help from a network of renowned freethinkers and dedicated doers, we made it happen. Trying to shape the institute over the first decade, we learned 10 important lessons that may be helpful for others in similar situations. (1) Securing a stable budget is essential, but a permanent challenge. (2) Structural international funding for a place-based institute is unlikely. (3) Having the institute outside the formal structure of a university gives liberty, but it is important to nurture good relationships. (4) An informal setting with ample scheduled time for walks, camp fires, and other leisure interactions helps participants build the trust and take the time needed to connect across disciplines and worldviews but can be seen as decadent by outsiders. (5) It is important to build resilience to the occasional reshuffling of cards inherent with government change. (6) It remains difficult for remote international board members to fathom the local dynamics and challenges inherent to running the institute on the ground. (7) Keeping the big idea alive while solving the continuous stream of everyday issues requires a combination of personalities with complementary skills in the dreamer-doer continuum. (8) There is a trade-off in selecting board members because the famous persons needed for credibility and for their extensive networks often have little time to contribute actively. (9) Truly linking science and arts requires long-term interaction between artists and scientists that are personally interested in this enterprise to allow for the necessary building of trust and mutual understanding. (10) A local sense of ownership is essential for long-term resilience.
\end{abstract}

Key Words: art and science; art-science collaboration; institute; resilience; SARAS; South America; sustainability

\section{CONCEPTION}

The conception of the idea for a South American Institute for Resilience and Sustainability Studies (SARAS: http://www.sarasinstitute.org) happened in 2006 during a conversation between Marten Scheffer and Néstor Mazzeo on a summer day in the garden of Scheffer's country house in the Netherlands. We had just run a project to sample 85 lakes on a climate gradient from tropical Brazil down to the tundra of Tierra del Fuego. In hindsight, what made this project so remarkable was the lack of funding. Not much more than the salaries of a Uruguayan and a Dutch PhD student were covered, whereas the expedition, meant to measure climate effects, required enormous logistic and analytical efforts. The approach was to seek scientists along the gradient who were willing to help identify suitable lakes and support the two students in the field. In return, we would analyze the samples and data together and publish together. The resulting web of scientists turned out to become a long-term network. Thanks to the trust built over the productive and exciting project, the web of cooperation is still alive and kicking one decade after the original project was finished. Such lively and resilient professional networks weaving South American and European scientists together were, and are, all too rare.

This experience of collaboration sparked the idea to create a place in South America that should become a lasting hub for weaving networks, this time not just for aquatic ecologists, but also for a broad spectrum of scientists working toward the common goal of building new insights that would help the region to realize sustainable and resilient futures and new insights to serve as inspiration for the world. At first, it was not much more than a vague dream, but, as we talked to different people about the idea, it gained both depth and momentum. Soon, it became clear that there were real possibilities to start building a hub in Uruguay, Mazzeo's home country. Indeed, the vision was met with such enthusiasm in countless conversations that we decided to give it a serious try. The reason for enthusiasm, of course, varied depending on the stakeholders. At the university and in the government, SARAS was seen as an opportunity to boost a dynamic of internationally recognized science and sustainability efforts in Uruguay. The international collection of scientists on whom we tested the idea expressed motivation to contribute to a movement that could really make a difference in a developing and beautiful part of the world. Also, among colleagues in science, we have perceived a worry about the restless and highly competitive kind of "fast science" that the current system invokes (Scheffer 2014, Scheffer et al. 2015). Several colleagues told us that a place like SARAS would hold the promise of a temporary escape from the perceived craziness.

\section{SHAPING THE VISION}

Scheffer asked a selection of highly regarded international colleagues that had become friends over the years to form the board, and Mazzeo mobilized key persons in Uruguay, equally seeking the combination of friendship and professional clout. It turned out that the powerful combination of diverse minds bound by trust and friendship was just what was needed to shape the vision further and mobilize the resources needed to get the ball rolling. At the first board meeting, it quickly became clear that if SARAS were to be a leading institute globally, rather than a copy of initiatives in Europe or the USA, it should draw on the strengths of the regions and incorporate the arts in collaboration with

${ }^{1}$ Wageningen University, The Netherlands, ${ }^{2}$ South American Institute for Resilience and Sustainability Studies (SARAS), Uruguay, ${ }^{3} \mathrm{CURE}$, Universidad de la República, Maldonado, Uruguay 
scientific and social scientific approaches to sustainability, resilience, and transformation. The South American continent has a particularly strong history of artists, including Nobel laureates in literature such as Pablo Neruda, Mario Vargas Llosa, Octavio Paz, Miguel Angel Asturias, and Gabriela Mistral. Strongly rooted in the South American culture, but internationally renowned, South American literature excels in the magical realism genre, creating worlds in which the most unexpected transformations happen. We felt that SARAS, by building a bridge between scientific and artistic approaches to resilience and transformation, could not only provide a particular and uniquely South American perspective, but could also enhance the organic connection between art and sciences, the two giants of the mind, and demonstrate how the two together could be powerful in generating novel ways of looking at complex problems in nature and society. As an illustration, several of the early board members were excited when finding out that the painter Salvador Dalí had fallen in love with René Thom's catastrophe theory in mathematics. Their discovery of the very last, unfinished painting by Dalí, portraying a critical transition, was perceived as a beautiful example of the inspirational interplay between arts and science, an iconic example for the first SARAS meeting. Making SARAS a place for exploration of such interplay was an exciting and motivating new vision and the beginning of a journey that would transform us all as we started to think about art, science, and the future of South America. To our surprise, we discovered that several members of the advisory board already practiced some art discipline such as music, close-up magic, or photography. Later, we learned that science Nobel Laureates are more likely to practice arts seriously on the side than most other scientists (RootBernstein et al. 2008), and that successful artists and scientists not only share essential character traits but also particular habits when working (Scheffer et al. 2017).

Another pillar of the thinking was the need for slow science (Scheffer 2014, Scheffer et al. 2015). Frances Westley, Steve Carpenter, Carl Folke, and Marten Scheffer had been part of an informal network organized by ecologist C. S. Holling, who brought together social and natural scientists on islands for rather open-ended workshops. Holling had a keen eye for selecting characters that were, as he framed it, "good on islands," meaning that rather than inviting dominant "silver-back" personalities defending their disciplinary turf aggressively, he was seeking open-minded thinkers that could bond also with persons that hold different worldviews. Those workshops created space for the emergence of new insights. Above all, those meetings revealed the catalyzing and trust-building effect of ample quality time in remote tranquil places. Indeed, from the resulting network of minds, the Resilience Alliance (https://www.resalliance.org/) eventually emerged, with its far-reaching impact on thinking and institutions. Bridges between different worlds of thought cannot be built otherwise. SARAS thus had to be a peaceful place with a friendly atmosphere and plenty of room for making campfires and wandering together in the hills or along the beach. To anchor our further explorations, we took great care in formulating our condensed vision statement:

SARAS generates critical insights allowing South America to build sustainable futures characterized by resilience and the capacity for transformation. It produces such insights through integration across a broad range of knowledge using innovative approaches ranging from mathematical models to arts. In its atmosphere, brilliant minds find peace to think deeply. At the same time, the kind and intense interaction at SARAS shapes a new generation of broad visionary thinkers and creators. The design and place of the building provide the context essential to such innovative synthesis.

\section{DESIGNING THE PLACE}

The next question we addressed was how we should shape such a magical environment. It soon turned out that the city of Maldonado was a strategically good place for two reasons. First, it fitted the policy of the national government and the public university to decentralize higher education and research out of Montevideo, the capital. Second, this was an area close to the hills, the shore, and the airport. The mayor of the town at the time, Oscar de los Santos, quickly adopted the SARAS plan as an opportunity and offered to choose a site from among many public lands. The current location turned out to have just the right atmosphere: 4 ha of land with a view of both mountains and ocean. While walking the land to explore its possibilities, we found a hand-written sign, written who knows when and forgotten on a tree, which read, "Aqui es donde no existe el tiempo" (here is where time does not exist). It seemed an omen: What else could we wish for slow science?

The next step was to create a vision of the actual building. Starting with a reflection on the architecture of places such as the Santa Fe Institute, we formulated a set of values we hoped to be incorporated in the structure. There was an open call for architects to make designs, followed by rounds of iterations between our wild ideas and the architect's interpretations. This process eventually resulted in a beautiful design (Fig. 1) that further stimulated thinking about the question of how to make this dream happen. Knowing that it would not be easy to find funding quickly for the entire set of buildings, we planned the work in two phases: first, a modest but pretty building with a small auditorium and some offices; second, the full project with three larger buildings and cabins to accommodate guests. The first modest building also would host a physician once a month to cater to the needs of the local community. We felt that this was important because we were invading their quiet space with our institute, built on public land. Indeed, as soon as we got the land, we organized a ceremonial event with the neighbors, planting a tree with the Culture and Education Minister, local government authorities, and the children in the local community to symbolize that something beautiful and important would grow here. Because the land was basically an old eucalyptus plantation, we also involved ecologists and landscape planners to redesign the vegetation using native species from the area.

\section{FIRST SERIES OF ACTIVITIES}

The lack of a building at the start did not prevent us from organizing activities to bring the SARAS idea to life. We organized an annual series of workshops (Fig. 2) planned in association with the annual board meeting so that the board members could participate and engage. A day of public lectures at each meeting helped building visibility and the public support needed from government ministries and the university. At the same time, each workshop would replicate and expand the collaborative experience of the lake study: each would bring a 
network of professionals to SARAS to weave together the South American network of which we had dreamed. We held workshops on resilience of freshwater resources in South America, sustainable fisheries in Latin America, and forest-grassland transitions at global scale. All of these initial topics were chosen to make best use of the existing contacts that the various board members had in those communities.

Fig. 1. Artist's impression of the three main buildings at night. The construction of these buildings is expected for a future phase of the Institute.

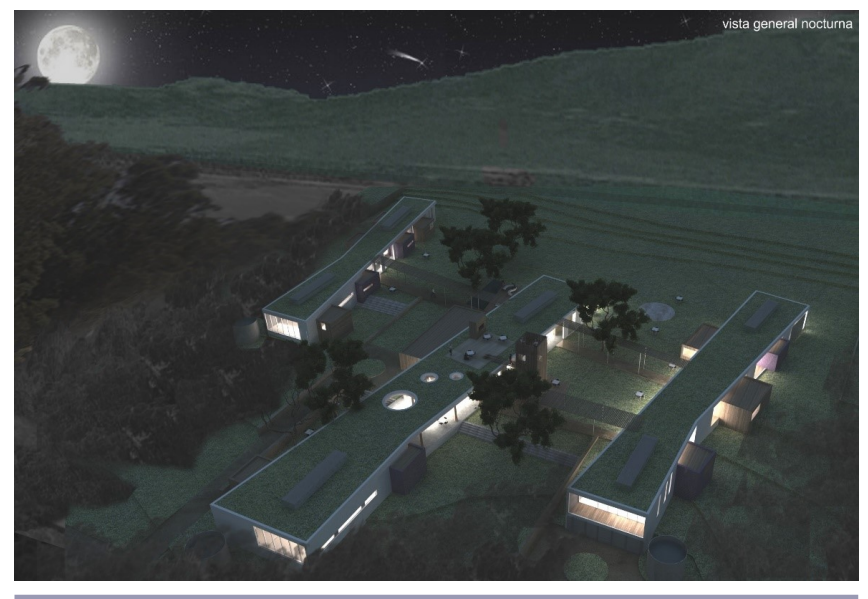

Fig. 2. Images from the first workshop at the South American Institute for Resilience and Sustainability Studies in March 2016.

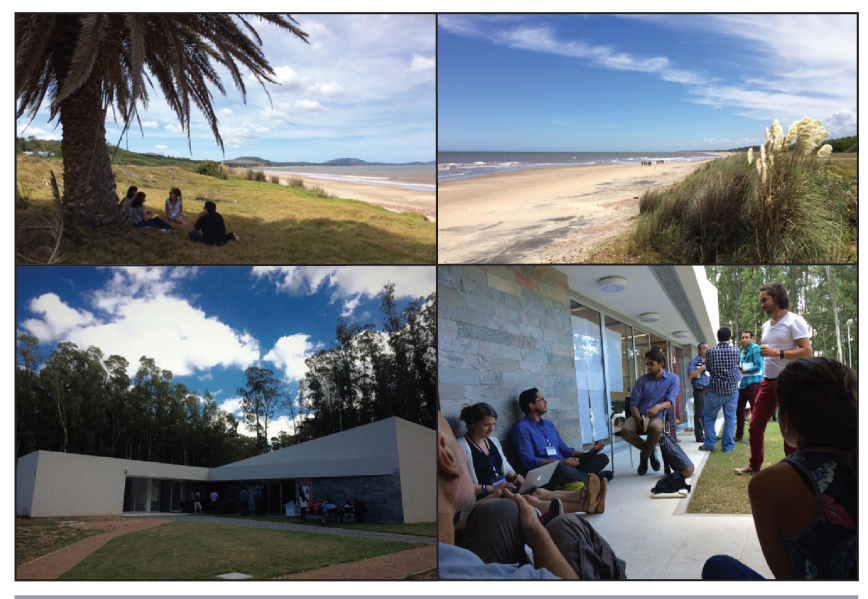

Inspired by the island meetings convened by C. S. Holling, the workshops had a free format with ample time for walks and shared dinners. Importantly, in addition to scientists, we also invited artists, predominantly from South America, to all meetings. We had brought Laurie Beth Clark on board, who was successful in identifying South American artists interested in transformations to sustainability. However, and perhaps unsurprisingly, in the first workshops, this marriage was uneasy. The science part always worked out fine, but it was not clear how best to combine the science productions with the artistic. We were unsatisfied with the two sitting side by side as parallel processes, but how to create greater integration? We decided to organize two workshops entirely devoted to the exploration of how arts and sciences could find synergy in exploring complex social-ecological problems. In the first of these, Frances Westley designed a workshop process that identified a range of themes, including science and magic, creative organizations, iconic imagery, education for creativity, and creative thinking, where processes and products in scientific and artistic domains seemed to be similar and mutually enhancing. Laurie Beth Clark designed a key experience in which mixed groups of scientists and artists walked the SARAS land and discovered quotations drawn from art and science (that complemented the prophetic "Aqui es donde no existe el tiempo" message) and then created an artwork that could stay in the forest for future groups to find.

Based on the excitement generated by this workshop and the collaboration, a set of deeper collaborations between artists and scientists were initiated, and a special feature of the journal Ecology and Society, devoted to art-science interaction, emerged (Westley et al. 2019). Both of these projects built an increasingly firm foundation of trust and bonding between the renowned artists and scientists. Part of this new ground gave raise to several initiatives involving science and art, such as an environmental poetry competition and a book on the subject. New ground was indeed explored, generating new ways of seeing and thinking.

The character of the meetings changed markedly in 2016, when the first building was ready to use. The workshop in March 2016 on futures of land use in South America brought the place to life, and the building turned out to have just the catalyzing effect on cross-disciplinary interaction that we had envisioned. Suddenly, the place was filled with a wonderfully diverse group of people who were discussing, drawing ideas on windows and whiteboards, and taking long walks on the beach down the road.

\section{TRANSFORMING TO A SECOND PHASE}

The subsequent advisory board meeting in December 2016 was a turning point. Thus far, most of the activities had been in Uruguay; with our small staff and many demands from local authorities to help out on applied issues, the annual workshops had been almost the only international activity. We realized that to make the quantum leap to becoming the regional institute we had originally envisioned, we would need to develop a regional web of initiatives rooted in Uruguay. To promote this development, we had invited key players that we envisioned as future partners for a 2-day workshop connected to the board meeting. To our relief, this worked out as expected. Again, the building proved a great place for brainstorming, breaking out in small groups on the beach (Fig. 3), and playing some intermezzo music in the great acoustics of the auditorium. We came up with a series of activities to be developed over the coming year, with a group of new and old friends that kicked off an impressive series of new activities in that year. Importantly, we also organized a major turnover of the board to rejuvenate, widen the expertise, broaden the network, and include more South Americans. Cristina Zurbriggen (Uruguay, social innovation studies), Esteban Jobbagy (Argentina, agronomy), Matilda Baráibar (Sweden, economic history), Patricia Balvanera (Mexico, socialecological systems), and Henrik Osterblom broadened our scope, provided a strategic link to new places, and ensured continuation 
of important connections (such as to the Stockholm Resilience Centre). Writer and translator Jessie Lee Kercheval provided a connection to the writer communities in Uruguay and the USA, and former Education Minister, dean, and mayor of Montevideo, scientist Ricardo Ehrlich, gave a solid link to Uruguayan politics and intellectual life. We also decided to have the board cochaired by one arts, social, or humanities person and one science person, beginning with Marten Scheffer and Laurie Beth Clark. The cochairs will rotate out asynchronously to ensure continuity, and we envision Latin American chairs heading a largely Latin American board in a few years. Rotating out after working together intensively on shaping such a beautiful initiative is quite emotional, and board members describe it as akin to seeing a lovingly raised child becoming adult and leaving the house. As a ritual, we asked all board members rotating out to leave their handprint on the wall (Fig. 4).

Fig. 3. Sunset at the Board meeting in December 2016.

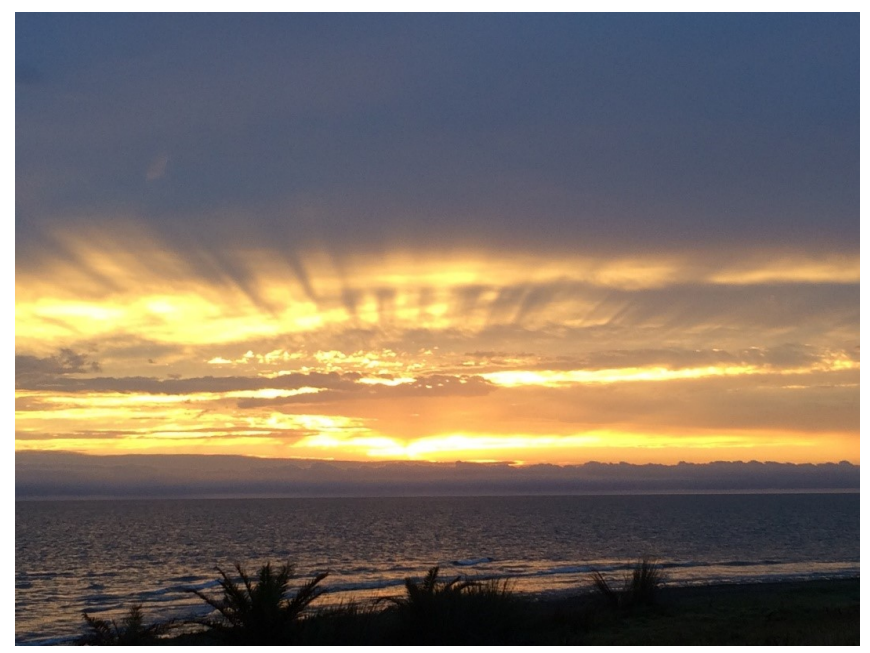

Fig. 4. Board members rotating out leave their handprints on the wall.

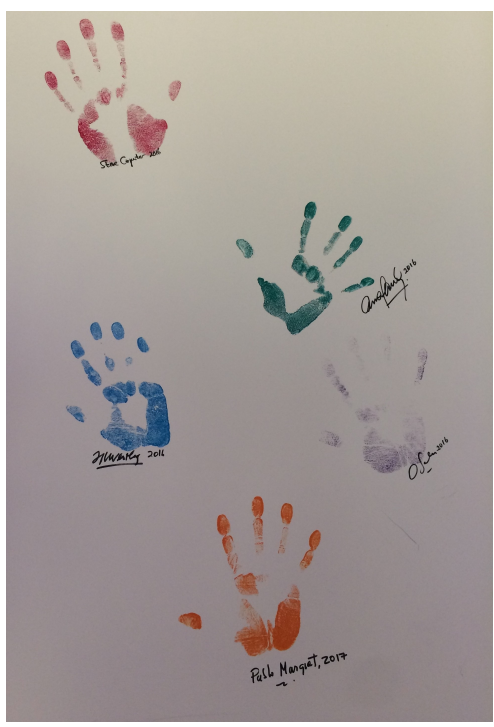

Watching the institute taking on a life of its own, with all its unexpected new initiatives and replenished energy, is profoundly gratifying. As may be seen on the SARAS website, activities have not only resulted in synthesis papers and reports, but also reach out through courses on SARAS land as well as web-based seminars and a wide range of other activities involving policy makers and local inhabitants, from young to old. Indeed, looking at the lively dynamics, it becomes clear that reality has started looking much like the original vision statement.

\section{CHALLENGES, DILEMMAS, AND LESSONS LEARNED}

Our essay thus far may give the impression of a smooth ride to success, but, of course, there have been countless challenges, dilemmas, and trade-offs along the road. Many things came up that we had not realized at the start. We learned from those and try to pass on some of the acquired tacit knowledge in this, perhaps most important, part of our essay. It is a reflection on the lessons learned. It is not a "don't try this at home" section. Rather, we can warmly recommend an adventure like this and would do it again. It all has worked out, but we might have been even more effective if we had realized the following things at the start.

Bootstrapping on a shoestring budget: Obviously, the first challenge is simply to find some funding. Much can be done as volunteer work, but flying in board members and getting some serious work done requires at least a minimal budget. Although Uruguay was very supportive of our ideas, carving out a budget was not altogether easy. After a few years, when the foundation was formed, however, a small budget allowing us to have a fulltime administrative assistant, a public relations and communications person, legal support, annual board meetings, and eventually, the first building and its maintenance was provided by the Uruguayan government. Still, we have been cashstrapped most of the time, and sometimes it was unclear even whether salaries could be paid by the end of the month.

International funding for a Uruguayan place: The initial expectation of Uruguayan authorities was that SARAS would bring in not only international scientists, but also international funds. Indeed, this happened when we secured budgets for several conferences from Spanish and U.S. funds and also through inkind support from Swedish and U.S. institutions. However, bringing in substantial international resources to realize the building and run an administrative staff turned out to be unrealistic. Clearer communication about this issue could have saved both parties much trouble.

Separate from the university, but linked: The national university Universidad de la República could seem the obvious place to host SARAS. However, experience with the Stockholm Resilience Center, which some of us were involved in initiating, was that a "loose coupling" with the more conservative academic structure was important. The two institutions, a conventional disciplinarybased academic organization and a creative interdisciplinary think tank, could coexist and ideally support each other, but their organization and processes had to be kept distinct. Traditional academic institutions are governed for reliable delivery of academic programs and "normal" disciplinary-based research. Creative think tanks have to be structured to stimulate innovation and creativity. The rules and restrictions of the former could stifle the latter. We therefore chose the formula of a foundation, where both the university and two ministries were partners. 
Slow science, but beware of using public funding for an "intellectual spa": The provost of the university that was assigned to help set up SARAS was very supportive and helpful. However, he was also very much aware of the tension that might arise from our vision of a peaceful place for contemplation and slow science in a beautiful setting. Indeed, he repeatedly reminded us of the need for austerity to avoid a decadent image. We were firmly convinced that slow science, including long walks on beaches, would be essential to realize our vision of cross-disciplinary novelty. At the same time, we clearly had to be constantly aware of the sensitivity around communicating this issue.

Be prepared for the unexpected: government change reshuffles the cards: We knew that a change of government can imply some instability in Latin America, where many of the individuals one deals with have positions de confianza, meaning that these government officers will be replaced after new elections. Even though the same political party stayed in place after the 2015 elections, large rearrangements inside the government caused SARAS to end up under a different ministry (housing, land planning, and environment), with an initial two-thirds budget cut. The need to work with the political cycle and to secure resource commitments at the appropriate times from the appropriate people were not built into the original blueprint for the institute, but quite clearly became an important factor. Having said this, we have been lucky to start in Uruguay at a moment when there was a long-term policy goal toward the development of interdisciplinary research and an expansion of higher education. Also, upon revitalizing the connections in the new setting, the budget has doubled, and commitment from the government has been reaffirmed.

Operating as a complex adaptive system: Living the shared dream served a beautiful vision for SARAS, like an overall attractor guiding emergence as in a complex adaptive system. In such systems, actors interact and connect with each other, often in unpredictable and unplanned ways, and from such interactions, broader scale patterns with new properties emerge, which then feed back on the system and influence the actors' interactions. Such an organic way of operating is nicely in tune with the resilience thinking and sustainability science focus of the transdisciplinary work of SARAS. There is emerging agreement that sustainability challenges require new ways of knowledge production and decision making (Lang et al. 2012), and SARAS is an adaptive experiment along those lines.

North-South friendships, but different worlds: As much as we appreciated each other, the distance, occasional lack of communication, and cultural differences among our South American, North American, and European participants played a role every once in a while. It was simply difficult to envision the entirely different South American on-the-ground institutional situation for the remote board members that were trying to follow all that happened and give good advice on directions to take. Board members would express frustration at being out of the loop in the year-long breaks between meetings. The Uruguayans experienced frustration at trying to move the project forward while being advised by mostly absentee directors who were unaware of the ways of local politics and bureaucracy.

Dreamers need doers and vice versa: Although Mazzeo and Scheffer had broad and appealing visions, both of them may also be classified as dreamers at times. Keeping a realistic work schedule up and running or negotiating hard when needed were not their strengths. The highly complementary roles of Osvaldo Sala, Mariana Meerhoff, and Ana Dubra were thus essential for success. The board meetings were always moments to get back to the big dreams, which were sometimes lost out of sight in the turbulent stream of everyday on-the-ground problem solving. We needed the complementary personalities, and the process also benefitted greatly from the alternation of brief dream phases (i.e., board meetings) and long periods of action.

Famous friends vs. active helpers: Our initial board consisted of famous scientists at the top of their career. All of them were already good friends of Scheffer or Mazzeo and were very enthusiastic to help think strategically at board meetings. However, all of them were also very busy running their own projects and research groups. Over the years, we realized that it would be important to include board members who were at earlier career stages and for whom SARAS would be an opportunity to actively develop their own network and work, thus creating a mutualistic relationship in which more real time could be spent on SARAS-related activities. Of course, the more actively these younger members were exposed to the visionary intent of SARAS (e.g., as students or colleagues of the first-generation board members), the less culture shock they were likely to encounter as they took up their new roles.

Diversity of ages enriches diversity in other dimensions: Young scientists and artists (i.e., current and recent students) are crucial for experiments in creativity. Young people have the time and motivation to try new things. More importantly, they have not already been told that certain things are impossible, and they are therefore willing to try, innovate, and find a way. Laurie Beth Clark and Steve Carpenter organized a collaboration of five graduate students from Wisconsin, USA who attended the 2015 SARAS meeting. The students' struggles, breakthroughs, and ultimate successes in art-science collaboration show that the SARAS vision works and maybe works faster with the young than with established artists or scientists. Development of expanded programs for younger artists and scientists could greatly accelerate the agenda of SARAS.

Slow science (and art) requires patience and creativity: It became obvious to us over the years that our instinct to engage artists to deepen our understanding of sustainability and transformation in a South American context was correct. However, it was also difficult. Convincing artists to come to workshops required bringing artists (initially Laurie Beth Clark) onto the Board. Keeping artists at the workshops required a much deeper understanding and appreciation of difference than we originally envisioned. So often, artists are treated by scientists as ancillary, to be brought in as a kind of intellectual decoration to the scientific process. At the same time, scientists sometimes feel that the artists see them as some sort of cold-blooded species with no sensations whatsoever. Over the years, we found that the rewards of collaboration (new and creative understandings) required a deep engagement to span this difference (Fig. 5). Initial confidence ("what a good thing this will be") gave way to polite tolerance ("I don't really get what they are doing but it will be over soon"), to irritation ("why am I being pushed to spend time on something that seems so arbitrary, alien, and irrelevant"), to curiosity ("hmmm, this is a foreign but potentially interesting approach"), 
to a different kind of confidence ("I may still not understand, but I can feel the power of this encounter"). Pushing artists and scientists into real collaborations in projects and papers accelerated this movement of deepening confidence. However, the journey itself takes time and patience if it is to be transformative.

Fig. 5. "Are artists and scientists really so distinct?" Cartoon by Sigrid Peterson. For more illustrations, including photographs of young artists and scientists at a South American Institute for Resilience and Sustainability Studies workshop, see http://edgeeffects.net/confluenceart-science/.

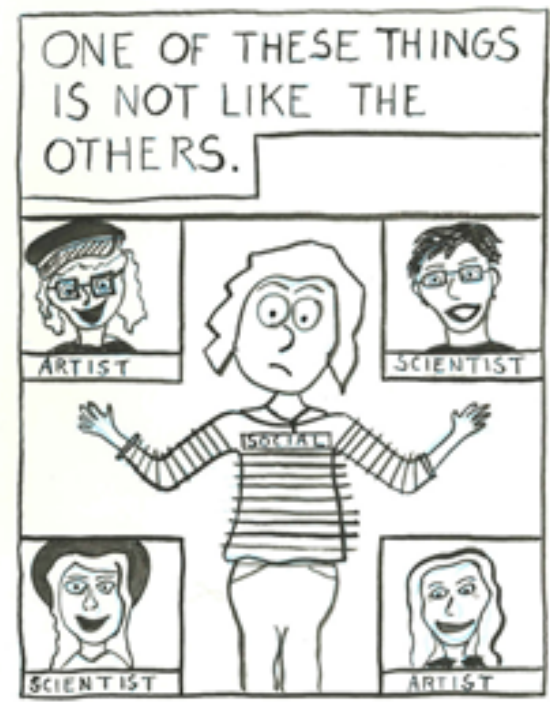

Global vs. regional ownership: In a similar vein, we came to the insight that, as much as we all wanted a global vision, it was really important to have the ownership and initiative be rooted in South America and also firmly in Uruguay. The sense of place, so important in the development of the SARAS experience, was distinctly Uruguayan. The energy that could continue to fuel the vision had to be present in individuals who were on the ground, in that place and at that time. As members of the founding board, this also meant that we had to trust that while the principles and intent that we had infused in the foundation of SARAS were resilient, the form and the specific content (programs, activities, relationships) would and should evolve to meet the ever-changing needs of that place and time.

\section{PROSPECT}

Of course, this story is open ended. SARAS is still small and fragile, and it is uncertain what the future will bring. What we have described as a logically unfolding sequence was in fact much more a voyage of discovery, a moving forward toward an imagined dream as opposed to building a structure from a blueprint for action. What powered the momentum forward throughout this somewhat erratic process? Is there a single most important factor? If so, will it persist to help SARAS flourish in the future? As we argued in the previous section, multiple mechanisms need to be in place. However, in hindsight, we think that the power of the vision has perhaps been most important in providing resilience to the initiative. Building on the initial ideas by Scheffer and Mazzeo, the first board carefully crafted that vision and outlined the logic of SARAS. A summary of the results of that inspired meeting can be found in Appendixes 1 and 2. The vision statement is pivotal.

Indeed, in the grand scheme of things, visions may well be the key to resilient, long-term, societal cooperation. As the historian Yuval Noah Harari argued, humans rule the world because we are the only animal that can believe in things that exist purely in our own imagination, such as gods, states, and human rights. Such powerful beliefs can persist for many generations. Back to our modest institute, it was indeed the original idea that created the momentum. Even if Mazzeo and Scheffer initially just developed it as a thought experiment, the response was overwhelmingly positive. This made it hard not to continue. Making it all work out, of course, was only possible upon the assembly of a team with a diverse set of complementary skills and a strong base of mutual trust that acted in a particularly fertile local context, much like in our shoestring lake research cooperation that inspired us in the first place. If SARAS can hold on to the dream in the continuous process of rejuvenating its diverse trust-based team, it will live on to be a growing source of inspiration and wisdom for the region.

Responses to this article can be read online at: http://www.ecologyandsociety.org/issues/responses. php/10983

\section{Acknowledgments:}

It will be clear from this essay that shaping SARAS has been a profoundly interactive enterprise for which we are first of all deeply grateful to the board members as cocreators. The first advisory board comprised Jordi Bascompte, Stephen Carpenter, Omar Defeo, Carl Folke, Pablo Marquet, and Frances Westley. Subsequently, the board was joined (in this order) by Osvaldo Sala, Laurie Beth Clark, Ana Parma, Eduardo Viola, Mariana Meerhoff, and Jorge Marcone. All of the boardmembers reflected on the text, and several brought up complementary views and memories that had escaped us. Steve Carpenter, in particular, helped in shaping the text and made us put more emphasis on the lessons learned. We are also grateful to the board members who joined in 2016 for taking over with new energy, visions, and ideas: Matilda Baráibar, Patricia Balvanera, Ricardo Ehrlich, Esteban Jobbagy, Jessie Lee Kercheval, Henrik Osterblom, and Cristina Zurbriggen. Lastly, SARAS would not have grown into the place it has become without key contributions from broad national and international communities that helped us shape our dream and make it real. It is hard to make this list complete, but it includes: Gabriel Aintablian, Ana Dubra, Paula Bianchi, Juan Cristina, Rodrigo Arocena, Gregory Randall, María Simón, Oscar de los Santos, Hernán Ciganda, Ruben Budelli, Matías Arim, Rafael Bernardi, Francisco Carriquiri, 
Alvaro Soutullo, Alejandro Nario, Matías Piaggio, Juan Rocha, Lisa Deutsch, Milena Holmgren, Michael Peterson, Angela Leible, Francisco Gazitua, Martha Castillo, Alejandro Turell, Claudia Anselmi, Raquel Bessio, Hugo Inda, Virginia Lucas, Manfred Steffen, Rafael Terra, and Micaela Trimble.

\section{LITERATURE CITED}

Lang, D. J., A. Wiek, M. Bergmann, M. Stauffacher, P. Martens, P. Moll, M. Swilling, and C. J. Thomas. 2012. Transdisciplinary research in sustainability science: practice, principles, and challenges. Sustainability Science 7(S1):25-43. https://doi. org/10.1007/s11625-011-0149-X

Root-Bernstein, R., L. Allen, L. Beach, R. Bhadula, J. Fast, C. Hosey, B. Kremkow, J. Lapp, K. Lonc, K. Pawelec, A. Podufaly, C. Russ, L. Tennant, E. Vrtis, and S. Weinlander. 2008. Arts foster scientific success: avocations of Nobel, National Academy, Royal Society, and Sigma Xi members. Journal of Psychology of Science and Technology 1(2):51-63.

Scheffer, M. 2014. The forgotten half of scientific thinking. Proceedings of the National Academy of Sciences 111(17):6119. https://doi.org/10.1073/pnas.1404649111

Scheffer, M., M. Baas, and T. K. Bjordam. 2017. Teaching originality? Common habits behind creative production in science and arts. Ecology and Society 22(2):29. https://doi.org/10.5751/ ES-09258-220229

Scheffer, M., J. Bascompte, T. K. Bjordam, S. R. Carpenter, L. B. Clarke, C. Folke, P. Marquet, N. Mazzeo, M. Meerhoff, O. Sala, and F. R. Westley. 2015. Dual thinking for scientists. Ecology and Society 20(2):3. https://doi.org/10.5751/ES-07434-200203

Westley, F., M. Scheffer, and C. Folke, editors. 2019. Reconciling art and science for sustainability. Ecology and Society Special Feature 112. In press. [online] URL: https://www.ecologyandsociety. org/issues/view.php/feature/112 
Shaping Shared Worldviews of Artists and Scientists; An Example

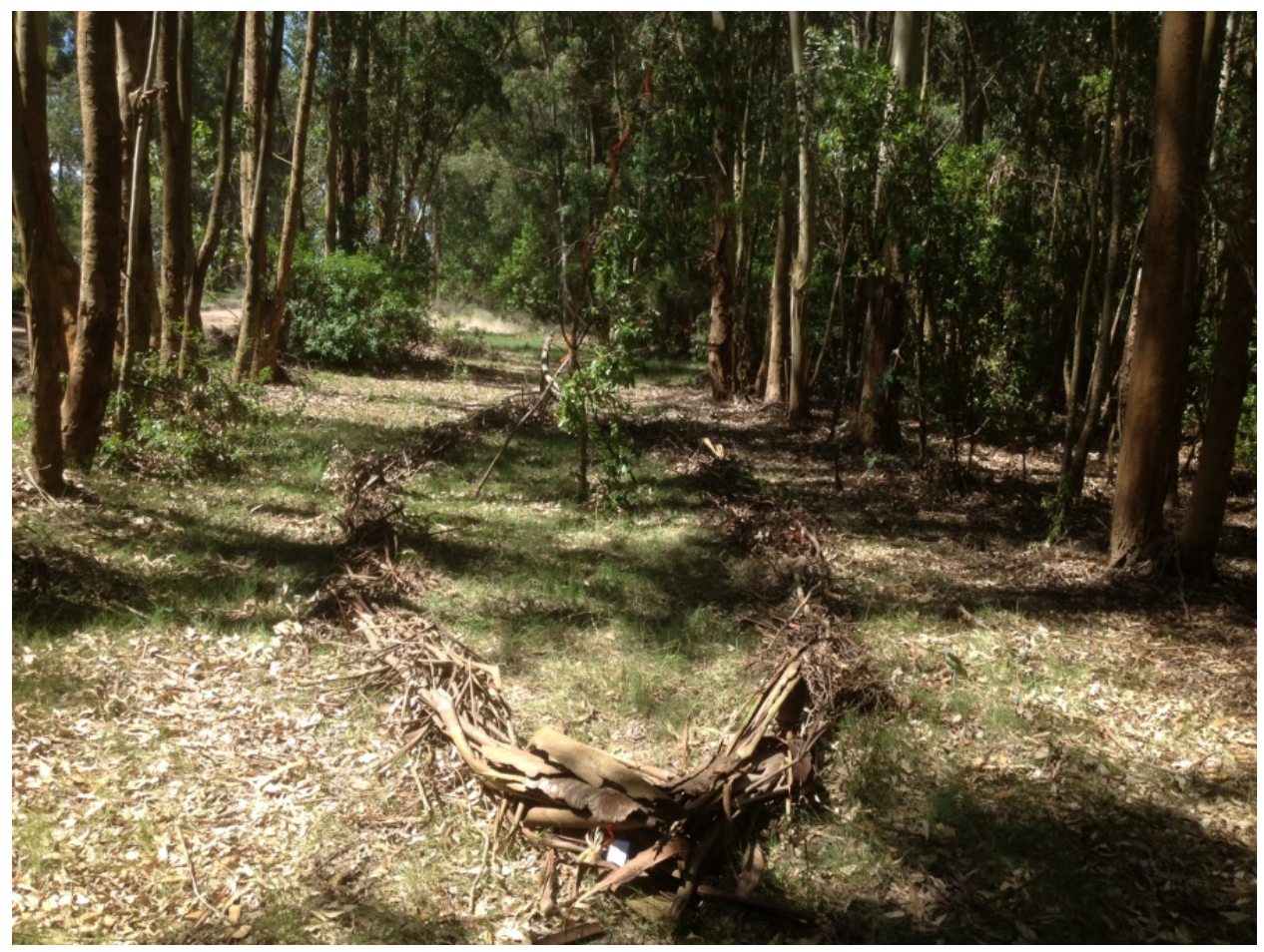

Reconnecting with the Ark

Installation at the SARAS land, December 2013 by Carl Folke, Francisco Gazitua, Mariana Meerhof and Marius Bakken

The Voyaging Canoe, the Viking Ship, the Ark - icons of human exploration in times of change, embedded in stories, beliefs and deep values of diverse cultures. Reconnecting with the Ark was performed in a beautiful alley of the SARAS land as a poetic way of capturing the essence of the resilience and sustainability challenge. Humanity is integrated with the Biosphere - the thin layer around the planet where life exists - and has evolved as part of it, shaping it, while simultaneously fundamentally dependent on its functions, diversity, and resilience. Reconnecting with the Ark is about riding the waves of change, exploring diverse and unknown pathways and the thresholds and tipping points in between. It is about experimenting, innovating, transforming, drawing on experience, insight, and wisdom. It is about the role of SARAS in our Biosphere future. People and nature are truly intertwined. Arts and science interplay. There is curiosity and wonder.

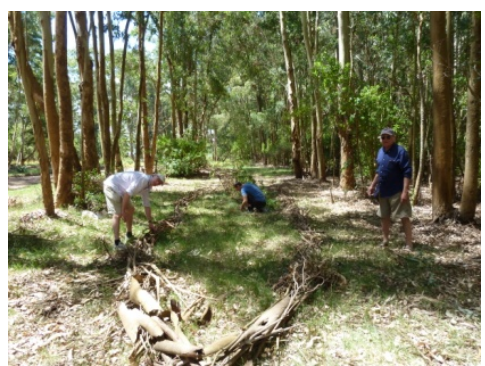

Building the Ark

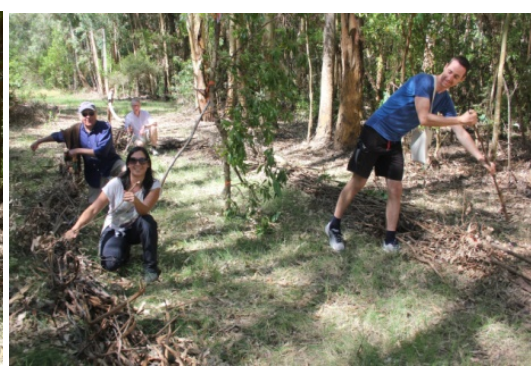

Riding the waves

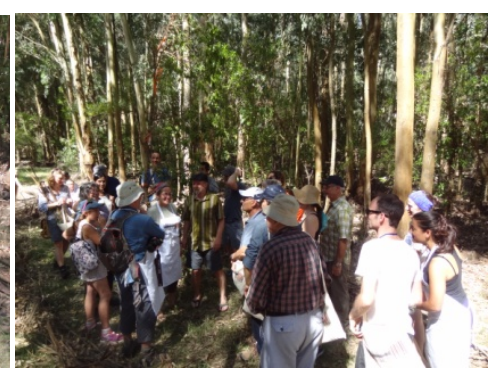

Bringing people on board 


\title{
Supplementary material
}

\author{
To the article "How to Build a Cross-Disciplinary Institute"
}

Written by the advisory board 5-6 January 2009, Montevideo

Marten Scheffer (The Netherlands), Osvaldo Sala (US/Argentina), Steve Carpenter (US), Carl Folke (Sweden), Frances Westley(US), Pablo Marquet (Chile), Jordi Bascompte (Spain), and from Uruguay: Omar DeFeo, Matías Arim, Néstor Mazzeo, Gabriel Aintablian.

\section{Vision Statement}

SARAS generates critical insights allowing South America to build sustainable futures characterized by resilience and the capacity for transformation. It produces such insights through integration across a broad range of knowledge using innovative approaches, ranging from mathematical models to arts. In its atmosphere brilliant minds find peace to think deeply. At the same time, the kind and intense interaction at SARAS shapes a new generation of broad visionary thinkers and creators. The design and place of the SARAS building provide the context essential to such innovative synthesis.

\section{Why SARAS?}

(Summarized by Carl Folke)

SARAS will put the South American research community in the centre of the international interdisciplinary research arena on sustainability, foster collaboration between SA and leading international scientists on resilience and sustainability worldwide and simultaneously serve as a hub for integrating researchers and PhD-students throughout South America to enhance the capacity of the region to deal with global change and necessary transformations.

SARAS will combine the powers of science, arts and the humanities for exploring and developing deeper understanding of the challenges and potentials of global change for human development, with a focus on South America. Explicit interaction between science, arts and the humanities in relation to global change is rare. South America holds great potential for such unique collaborations that will generate new insights and innovative knowledge integration with powerful images and major implications for sustainable futures.

SARAS will develop new ways of teaching and training for knowledge integration that will be exemplary worldwide.

In many SA countries there is lack of an independent and confident scientific group that could be taken as reference for political and social environmentally-related problems. In this sense, SARAS will 1) become a permanent reference on sustainability issues that could overcome 
short-term and in many cases drastic changes in the political context; 2) be used by policy makers and the society as a whole in order to provide potential solutions/opinions to assess particular social-ecological problems.

The above is particularly important in SA, because of: 1) the critical importance of natural resources and ecosystem services in SA economies; 2) the unwise and erratic management practices of them; 3) the lack of long-term policy directed to provide a sustainable use of ecosystem services founded on solid social-ecological knowledge; 4) the lack of interdisciplinary studies directed to address the intrinsic complexity of social-ecological systems; 5) the lack of integration of key stakeholders when planning and implementing policy for sustained used of natural resources (governance issues).

In SA there is the largest gradient in socio-economic conditions and in the extent of the impact by humans on ecosystems (i.e. from the most pristine to the most polluted worldwide). These gradients could be seen as model systems directed to identify the mechanisms operating beyond human actions.

\section{Why South America?}

(Summarized by Osvaldo Sala)

SARAS is focused on South America and its headquarters are located in Uruguay because South America is an extraordinary laboratory to make progress in understanding and training on issues related to sustainability and resilience of social and ecological systems. South America is such an extraordinary laboratory because of four reasons:

1. Large social and environmental contrasts exist in South America

2. History of turbulent change and transformation in social and environmental realms

3. A rich artistic understanding of transformation

4. Strong link of people to natural resources and the environment

South America harbours strong social and environmental contrasts. The largest pristine ecosystems of the world such as the Amazon Forest are usually juxtaposed to the most degraded ecosystems of the world. Erosion, soil degradation, and air and water pollution are common phenomena that coexist within the region with the largest reservoir of biodiversity in the world. South America has the largest social and economic inequalities of the world. Rich neighbourhoods contrast with adjacent shanty towns. Similarly, large inequalities exist between city and rural environments, and in health and education. These strong differences could be used to identify the mechanisms creating inequalities and suggest strategies to achieve sustainability.

The South American Region has had a history of turbulent change and transformation. Politically, the region has recently shifted from dictatorships to democracies and includes a more distant history of colonialism and liberation. Environmental transformation has been huge driven by pre-colonial civilizations and currently by agricultural expansion.

South America has nurtured an artistic community that has carved a unique international niche based on its ability to depict sudden transformation. For example, the magical realism pioneered 
by Gabriel García Márquez is an extraordinary representation of this ability to articulate and understand change.

People in South America are strongly linked to natural resources. A large fraction feeds itself with the food that they raise and consequently are directly affected by pests and droughts. Similarly, most South Americans meet their health needs using local species and traditional medicine. The scarcity of resources limits the ability for buffering people from natural disasters including droughts and floods that severely affect their livelihoods.

\section{Why Synthesis?}

(Based on a report of an NSF group headed by Steve Carpenter, current version edited by Marten Scheffer)

Synthesis is the process of putting together disparate data, concepts or theories to create new knowledge, tools or other innovations. Synthesis is essential for progress in ecology and the environmental sciences, which are inherently interdisciplinary. Ecology is centrally and traditionally one of the biological sciences, yet it embraces elements of the geosciences and social sciences. Moreover, applied ecology connects closely to engineering. Computational sciences are essential in all forms of ecology and environmental science, and the co-evolution of ecology and cyber-infrastructure greatly accelerates synthesis.

Synthesis is increasingly important due to changes in knowledge itself, the culture of the discipline, and society's demands for education and information. The huge and growing body of knowledge confounds traditional mechanisms of innovation and is manageable only through synthesis. Because synthesis engages diverse scientists with diverse expertise, it is capable of vetting vast amounts of information for use by other scientists, educators or society.

Education demands synthesis, because it depends on integration of information. Conversely, education is essential for synthesis, because we need more experts trained in the skills of synthesis. These skills are not within the purview of any one discipline, yet they can and must be taught. Obviously, in its education and training SARAS should focus particularly on skills \& tools for knowledge integration, interdisciplinary collaboration. (It will rely on University departments for disciplinary knowledge.)

Synthesis is also a good focus for SARAS because this kind of centers can bring unique capabilities and unmatched opportunities for synthesis due to the intensity of interaction among scientists, great diversity of participation, emergence of new networks among scientists, financial and logistic efficiencies, and the close interaction of ecology with cyber-infrastructure and education. The high tenor of creativity, innovation and productivity at Centers simply cannot be matched by any other mechanisms for synthesis.

\section{Why the full continuum of approaches from science to policy?}

(summarized by Pablo Marquet with scheme by Frances Westley)

While SARAS is committed to synthesis, it will not rigidly limit itself to this particular domain in the range of approaches from fundamental science to policy. One of SARAS unique features is its commitment with the generation of knowledge that transcends disciplinary boundaries, and 
capitalizes on synthesis and integration (knowledge without walls). In particular, we support the view that the Resilience and sustainability of the human enterprise on earth requires synthesis and integration of knowledge within science in a dialog with the arts and humanities. We see this as one of most important transformation that need to happens in order to tackle the global problems humanity faces and to assure that we will create a sustainable future with better humans making better decisions on how to interact among themselves and with the environment. A fundamental component of our strategy is to produce societal/policy changes through the training of new generation of scientists in the culture of transdisciplinary work and integration. Thus, our mission is the generation of knowledge, through synthesis and integration, and its dissemination through training and education in a way that it becomes a source of policy changes.

\section{Why Art?}

(summarized by Frances Westley)

The goal of SARAS is sustainable futures and resilience for South America. As a science and research driven initiative, we are focused on the role of new knowledge in contributing to this goal. Within that we anticipate a number of steps in moving from knowledge to action to solve problems (see schematic representation above).

Within that continuum our expertise/interest is located mostly around knowledge integration with particular emphasis on the integration of science, arts and humanities. This is because our interest is in transformation, in creative questioning and in holistic explanations/approaches. This is something we feel is shared by both artists and scientists.

* Science and art are the two central expressions of human creativity. As that, they could bring mutual contributions to the creation process.

* Art is a strong way to impact society with a different language that reaches people with very different educations and backgrounds (popular appeal and contact)

* Art takes synthetic and holistic approaches - inherently understands the complexity and interconnection of system variables

* Art is often concerned with transformations (see Why South America) 


\section{How to Design the Building?}

The physical environment of an institute has tremendous impact on social dynamics. Since the right kind of interaction is crucial for the synthesis we envision, the building has to be designed specifically for that. We can learn a lot from earlier mistakes and successes in this sense. If you google "cave and commons" a lot can be found on this philosophy and related ones for shaping workspace. Talking to a range of scientists that have worked and interacted in many places a few commonly emerging suggestions are:

- Have a common area with informal corners with sofa's, armchairs, a big espresso machine etc.

- Have a 'bar' where cocktails etc. are served at 5 or so creating a habit for everyone to meet there before dinner and chat informally (the roof terrace?).

- Have many large windows

- Have a good outside space with shade, seats, and a roof terrace

- Have differently sized tables where small groups can meet

- Have numerous whiteboards, and/or possibility to write (erasable) on the windows and tables

- Have no offices for scientists (people come to cooperate, not to isolate themselves; they can work on the desk in the sleeping room, connected by wireless network)

\section{Specific Space requirements:}

- Meeting room for $40+$ Two rooms for 10

- relatively large informal common area with sofa-corners

- 10 high quality sleeping rooms (with bathroom; no tv needed, but good working desk and good beds) +20 simpler sleeping facilities

- Two cottages that can hold a family or small group (5+5) (again should have good working desk and beds)

- Offices for secretary and managing director

- Kitchen + dining room for $40+$ bar

- outside: shade; walking paths; pool(?); barbeque; working/sitting corners

- shaded roof terrace with a view of the Sierra de las Animas and the Ocean

\section{Technical facilities:}

- Fast wireless internet

- Printers and 2 desktop computers (most will bring their lap-tops)

- Video conferencing facility

- Lots of blackboards (or whiteboards with pens and erasers that work)

\section{Guiding the design and construction}

- These visions of the building by the future users need to be well and completely communicated to the architects taking part in the open call for the design. The advisory board should be involved in judging the competing designs.

- It is very important that construction is closely guided to ensure that the resulting building and grounds make the best use of the natural features of the site and buildings that meet the vision of the designers.

- Also, there should be good long-term management goals for the vegetation, landscaping etc.? 